\title{
THE ANNUAL MEETING OF THE SOCIETY
}

The forty-fourth Annual Meeting of the American Mathematical Society was held at Butler University, Indianapolis, Indiana, from Tuesday to Thursday, December 28-30, 1937, in conjunction with the meetings of the American Association for the Advancement of Science, the Mathematical Association of America, the Association for Symbolic Logic, and the Institute of Mathematical Statistics.

There were four general and eight sectional sessions of the Society, at which three addresses and ninety-three research papers (fifty-nine in person) were given. All sessions were in Jordan Hall, Butler University, except the Gibbs Lecture, which was held in the ballroom of the Antlers Hotel.

Arrangements for the meetings were made by a committee of which Professor K. P. Williams was chairman and Professors Juna L. Beal and B. C. Getchell were the local members. Through the generosity of Butler University, rooms were available in the nearby fraternity and sorority houses. The Marott Hotel was used as the headquarters for mathematicians.

The membership attendance was the second largest at an Annual Meeting, the record being two hundred eighty-two in 1928 at New York City. More than four hundred persons registered, among whom were the following two hundred seventy-one members of the Society:

V. W. Adkisson, R. P. Agnew, L. V. Ahlfors, A. A. Albert, E. S. Allen, C. B. Allendoerfer, Warren Ambrose, V. A. Ames, N. L. Anderson, H. F. Archibald, R. C. Archibald, Emil Artin, Max Astrachan, J. V. Atanasoff, C. S. Atchison, W. L. Ayres, R. W. Babcock, H. W. Bailey, E. F. Beckenbach, F. A. Beeler, M. M. Beenken, A. A. Bennett, William Betz, G. D. Birkhoff, G. A. Bliss, Henry Blumberg, L. M. Blumenthal, O. K. Bower, M. G. Boyce, J. W. Bradshaw, R. W. Brink, H. W. Brinkmann, F. L. Brooks, G. S. Bruton, H. E. Buchanan, C. T. Bumer, R. S. Burington, L. E. Bush, Jewell H. Bushey, W. E. Byrne, W. D. Cairns, B. H. Camp, E. J. Camp, H. H. Campaigne, M. E. Carlen, W. E. Cederberg, J. H. Chanler, Alonzo Church, E. H. Clarke, M. D. Clement, L. M. Coffin, L. W. Cohen, J. B. Coleman, E. G. H. Comfort, N. B. Conkwright, A. H. Copeland, Max Coral, J. J. Corliss, A. P. Cowgill, L. C. Cox, A. T. Craig, H. B. Curry, D. R. Curtiss, J. H. Curtiss, E. H. Cutler, D. R. Davis, H. T. Davis, W. M. Davis, D. B. DeLury, A. H. Diamond, L. L. Dines, E. L. Dodd, D. M. Dribin, W. E. Edington, Churchill Eisenhart, W. H. Erskine, G. C. Evans, G. W. Evans, H. P. Evans, B. F. Finkel, C. H. Fischer, W. W. Flexner, M. M. Flood, K. W. Folley, L. R. Ford, F. J. Gerst, B. C. Getchell, H. A. Giddings, H. H. Goldstine, G. D. Gore, Cornelius Gouwens, F. L. Griffin, P. R. Halmos, Israel Halperin, D. C. Harkin, E. G. Harrell, M. C. Hartley, M. L. Hartung, J. O. Hassler, Alan Hazeltine, E. R. Hedrick, C. B. Hennel, M. R. Hestenes, R. U. Hightower, T. H. Hildebrandt, R. C. Hildner, D. L. Holl, T. R. Hollcroft, I. M. Hostetter, E. M. Hove, M. G. Humphreys, E. V. Huntington, Witold Hurewicz, W. R. Hutcherson, C. A. 
Hutchinson, D. H. Hyers, M. H. Ingraham, Dunham Jackson, E. D. Jenkins, Fritz John, H. F. S. Jonah, A. J. Kempner, J. M. Kinney, S. C. Kleene, E. E. Knight, L. A. Knowler, H. L. Krall, J. H. Kusner, O. E. Lancaster, Cornelius Lanczos, G. B. Lang, R. E. Langer, C. H. Langford, C. G. Latimer, C. A. Lester, G. H. Ling, M. I. Logsdon, W. R. Longley, Brother Louis De La Salle, R. G. Lubben, E. J. McShane, C. C. MacDuffee, Saunders MacLane, H. M. MacNeille, P. T. Maker, Dorothy Manning, Anna Marm, R. H. Marquis, William Marshall, R. S. Martin, R. G. Mason, A. E. Meder, Karl Menger, H. J. Miles, A. N. Milgram, W. E. Milne, W. L. Miser, Virginia Modesitt, C. N. Moore, M. G. Moore, R. L. Moore, T. W. Moore, Marston Morse, E. J. Moulton, F. R. Moulton, G. C. Munro, S. B. Myers, A. L. Nelson, C. A. Nelson, C. J. Nesbitt, C. V. Newsom, M. J. Norris, F. C. Ogg, E. G. Olds, P. S. Olmstead, T. P. Palmer, E. W. Paxson, S. E. Pence, E. D. Pepper, P. M. Pepper, O. J. Peterson, H. P. Pettit, A. E. Pitcher, H. S. Pollard, V. C. Poor, G. B. Price, Irene Price, Tibor Radó, G. Y. Rainich, E. D. Rainville, W. C. Randels, J. F. Randolph, S. E. Rasor, F. W. Reed, Harriet Rees, Francis Regan, W. T. Reid, Haim Reingold, R. G. D. Richardson, P. R. Rider, H. L. Rietz, R. F. Rinehart, Robin Robinson, J. B. Rosenbach, J. B. Rosser, M. F. Rosskopf, E. H. Rothe, D. A. Rothrock, L. L. Runge, S. T. Sanders, R. G. Sanger, A. C. Schaeffer, O. F. G. Schilling, I. J. Schoenberg, Henry Schultz, W. E. Sewell, M. E. Shanks, W. A. Shewhart, L. S. Shively, C. G. Shover, D. T. Sigley, C. H. Smiley, M. F. Smiley, A. H. Smith, F. C. Smith, G. W. Smith, G. W. Starcher, N. E. Steenrod, H. E. Stelson, Guy Stevenson, G. R. Stibitz, E. C. Stokes, R. W. Stokes, E. B. Stouffer, Otto Szász, J. S. Taylor, M. E. Taylor, H. P. Thielman, H. S. Thurston, E. W. Titt, C. B. Tompkins, C. C. Torrance, W. J. Trijitzinsky, P. L. Trump, A. W. Tucker, Henry VanEngen, H. E. Vaughan, H. S. Wall, S. E. Warschawski, J. H. Weaver, D. L. Webb, M. J. Weiss, E. L. Welker, N. W. Wells, G. W. Whaples, J. J. Wheeler, O. L. Wheeler, G. T. Whyburn, W. M. Whyburn, D. V. Widder, L. R. Wilcox, S. S. Wilks, K. P. Williams, A. H. Wilson, Wilfrid Wilson, L. A. Wolf, M. C. Wolf, H. E. Wolfe, F. E. Wood, Kathryn Wyant, M. M. Young.

The opening meeting of the American Association for the Advancement of Science was held Monday evening in the Murat Temple. Professor E. G. Conklin delivered his retiring presidential address on the subject Science and ethics. Dean G. D. Birkhoff, President of the Association, served as chairman. The address was followed by a reception for all members of the Association and affiliated societies.

The meetings of the Society began Tuesday morning with two sections, Algebra and Analysis, and Topology. That afternoon, the Society met again in two sections, Analysis, and Geometry and Algebra. The presiding officers at these four sectional meetings were, respectively, Professors W. M. Whyburn, R. L. Moore, and T. H. Hildebrandt, and Dean E. B. Stouffer.

The fourteenth Josiah Willard Gibbs Lecture was delivered Tuesday afternoon at four-thirty by Charles A. Kraus, Research Professor of Chemistry at Brown University, before a joint meeting of the Society and the Association for the Advancement of Science, at which Dean G. D. Birkhoff presided. The subject was The present status of 
the theory of electrolytes. The attendance at this lecture was about five hundred.

At the beginning of the general session Wednesday morning, President J. W. Putnam, of Butler University, gave a brief address of welcome. This general session included, also, a business meeting and the annual election. President R. L. Moore presided.

Wednesday afternoon, Professor Alonzo Church, of Princeton University, gave an address entitled The constructive second number class at a general session at which Professor D. R. Curtiss presided. Following this, the Society met in two sections, Mathematical Logic and Algebra. The section on Mathematical Logic was a joint session with the Association for Symbolic Logic at which Professor E. V. Huntington presided. Professor A. A. Albert presided in the Algebra section.

The Society met Thursday morning in two sections, Mathematical Statistics and Analysis. The section on Mathematical Statistics was a joint session with the Institute of Mathematical Statistics under the chairmanship of Professor W. A. Shewhart, President of the Institute. Professor E. J. McShane presided in the Analysis section.

On Thursday afternoon, at a joint session of the Society, the Mathematical Association of America, the Econometric Society, the Institute of Mathematical Statistics, and Sections $A$ and $K$ of the Association for the Advancement of Science, Professor G. C. Evans, of the University of California, gave an address as retiring Vice President of the Association for the Advancement of Science and Chairman of Section A. The subject was Mathematical progress in theoretical economics. Professor W. D. Cairns, Vice President of the Association for the Advancement of Science and Chairman of Section A, presided.

Sessions of the Mathematical Association of America were held on Thursday afternoon and Friday morning.

A joint dinner for members of the mathematical organizations and their guests was held on Wednesday evening in the Marott Hotel. The attendance was three hundred twenty-five. Dean G. D. Birkhoff, Dr. F. R. Moulton, Dr. J. McKeen Cattell, and Miss Martha Hildebrandt were guests of honor. Professor R. E. Langer was toastmaster. In recognition of the close ties of the mathematical organizations with the American Association for the Advancement of Science, he introduced, as the first speaker, Dean G. D. Birkhoff, President of that Association, followed by the Permanent Secretary, Dr. F. R. Moulton. Two speakers, Professors G. C. Evans and T. H. Hildebrandt, represented the mathematicians. Professor G. T. Whyburn 
presented resolutions, which were adopted unanimously, thanking the President and members of the Mathematics Department of Butler University, the local committee, and the Marott Hotel for their excellent arrangements and cordial hospitality.

On Thursday afternoon, following the Association meeting, a tea was given in the Recreation Room, Jordan Hall. The hosts and hostesses were President and Mrs. J. W. Putnam, Dean and Mrs. G. A. Ratti of Butler University, and the members of the Butler University Department of Mathematics.

The meeting of the Board of Trustees at noon, December 28, in Room 127, Jordan Hall, did not have a quorum present. An adjourned meeting, therefore, was held on January 2 at 7:30 P.M. in the Office of the Society in New York City.

The Council held a meeting in the Marott Hotel on Tuesday evening, December 28, following dinner. There was also an adjourned meeting of the Council at 1 P.M., Thursday, December 30, in Jordan Hall.

At the business meeting, Wednesday morning, December 29, the annual election closed. Announcements were made of the results of the election and of the decisions of the Council in various matters.

Professor William Marshall and Dr. E. R. Lorch were tellers for the election. A total of two hundred fifty-four ballots were cast. The following officers and members of the Council were declared duly elected:

Vice Presidents, Professors R. E. Langer and J. F. Ritt.

Secretary, Dean R. G. D. Richardson.

Associate Secretaries, Professors W. L. Ayres and M. H. Ingraham, and Dean T. M. Putnam.

Treasurer, Professor B. P. Gill.

Members of the Editorial Committee of the Bulletin, Professors L. M. Graves and P. A. Smith.

Member of the Editorial Committee of the Transactions, Professor Einar Hille.

Member of the Editorial Committee of the Colloquium Publications, Professor J. R. Kline.

Member of the Editorial Board of the American Journal, Professor T. H. Hildebrandt.

Members of the Council, Professors Philip Franklin, A. D. Michal, John von Neumann, J. L. Synge, and W. J. Trjitzinsky.

It was announced that the following fifty-two persons had been elected to membership in the Society:

Professor Emil Artin, University of Notre Dame; 
Mr. Frank Boehm, Manager, Life Insurance, New York, N. Y.;

Professor Caldwell Elwood Boulware, Barber-Scotia College, Concord, N. C.;

Mr. Reynolds Driver Brown, Philadelphia Storage Battery Company, Philadelphia, Pa.;

Mr. Robert Buchanan, Golden Gate College, San Francisco, Calif.;

Mr. Everett Tyler Burton, Bell Telephone Laboratories, New York, N. Y.;

Miss Mary Agnes Campbell, Lamar College, Beaumont, Texas;

Professor Clifton O'Neil Carey, University of Michigan;

Mr. Charles Lemuel Carroll, University of North Carolina;

Miss Esther A. Compton, Wood Junior College, Mathiston, Miss.;

Professor John Cleveland Cothran, Duluth State Teachers College, Duluth, Minn.;

Dr. Ainsley H. Diamond, University of California at Los Angeles;

Dr. Churchill Eisenhart, University of Wisconsin;

Professor Hilbert Adam Fisher, North Carolina State College, Raleigh;

Mr. George Nelvin Garrison, College of the City of New York;

Mr. Paul Richard Halmos, University of Illinois;

Mr. George Madison Harner, Marquette University, Milwaukee, Wis.;

Mr. Richard Manning Hermes, University of Santa Clara, Santa Clara, Calif.;

Dr. Doncaster George Humm, Los Angeles, Calif.;

Miss May Baggott Kelly, Bulkeley High School, Hartford, Conn.;

Mr. James Ronald Fraser Kent, University of Illinois;

Dr. Thomas J. Killian, Barkon-Tube Lighting Corporation, Long Island City, N. Y.;

Mr. Charles Henry Lehmann, Cooper Union, New York, N. Y.;

Rev. James Luke McKenney, O.P., Providence College, Providence, R. I.;

Professor Michel George Malti, Cornell University;

Mr. Ralph Mansfield, Armour Institute of Technology;

Miss Lillian Moore, Far Rockaway High School, Far Rockaway, N. Y.;

Mr. Marvin G. Moore, Indiana University;

Dr. David Carruthers Murdoch, Yale University;

Professor James O. Patterson, St. Charles Seminary, Philadelphia, Pa.;

Professor Robert Leonidas Peguese, Allen University, Columbia, S. C.;

Professor George Whitefield Petrie, South Dakota State School of Mines, Rapid City;

Dr. Harriet Rees, University of Utah;

Dr. Robert Weir Rempfer, Rensselaer Polytechnic Institute;

Mr. William Garfield Riley, Washington, D. C.;

Dr. Erich H. Rothe, Penn College, Oskaloosa, Iowa;

Professor Phillip Justin Rulon, Harvard University;

Mr. George Sandalls, Bell Telephone Laboratories, New York, N. Y.;

Dr. Arthur Sard, Queens College, Flushing, N. Y.;

Dr. James K. Senior, University of Chicago;

Mr. Samuel Schwartz Smith, University of Utah;

Dr. David Barnard Steinman, New York, N.Y.;

Mr. Charles Edward Stevens, Hofstra College, Hempstead, N. Y.;

Dr. George Robert Stibitz, Bell Telephone Laboratories, New York, N. Y.;

Dr. George Booth Van Schaack, University of Rochester;

Mr. Holmes Hinckley Welch, Brooks School, North Andover, Mass.;

Dean Daniel E. Whelan, Loyola University of Los Angeles;

Mr. Harold C. Wiedeman, University of Denver;

Mr. Charles Wiley Williams, Washington and Lee University; 
Dean Claude Rodolphus Wood, State Teachers College, Jacksonville, Ala.;

Mr. Richmond T. Zoch, Weather Bureau Office, Washington, D. C.;

Mr. Max Zwillinger, U. S. Navy Yard, Washington, D. C.

It was reported that the following had been elected as nominees on the Institutional Memberships of the various institutions and departments :

Brown University: Messrs. Edward Maurice Beesley and Mahlon Marsh Day, Dr. Douglas Derry, and Mr. Charles Samuel Sutton.

University of California at Los Angeles: Messrs. Robert Henry Sorgenfrey and Paul Alexander White.

Department of Mathematics, University of Chicago: Mr. Leonidas Alaoglu, Miss Evelyn R. Garbe, and Messrs. Sam Perlis and Leonard Tornheim.

Members of the Department of Mathematics of the College of the City of New York: Mr. Julian H. Blau.

Columbia University: Messrs. Ellis Robert Kolchin and Howard Levi, Miss Ethel Harriet Raybould, Miss Leona Rosenthal, and Messrs. Rubin Schatten and Walter Moakler Wynne.

Cornell University: Messrs. Charles Erwin Clark, Edwin Alfred Sydney Galbraith, Walter Joel Harrington, Karl Johannes, Donald S. Miller, Milton Everett Terry, George Brinton Thomas, and William Dean Wray.

Duke University: Messrs. Grady Craven Frank and William Gillespie McGavock. Department of Mathematics, University of Illinois: Messrs. Warren Ambrose, Ross Allen Beaumont, James Dow Campbell, C. Ronald Cassity, Foster Leroy Dennes, James McQueen Dobbie, and Joseph J. Eachus, Miss Margaret Mary Hansman, Messrs. Donald Eugene Kibbey, Andrew O. Lindstrum, Philip Tillotson Maker, Carl E. Marshall, Donald Rhea Shreve, David Wright Starr, Everett Linus Welker, and F. Joachim Weyl.

Institute for Advanced Study: Professors Erich Hecke (Mathematisches Seminar der Universität, Hamburg), Václav Hlavatý (University of Prague), and Tadasi Nakayama (Osaka Imperial University), Dr. Cecil James Nesbitt, Mr. Maxwell Herman Alexander Newman, and Dr. Frank Smithies.

Department of Mathematics, State University of Iowa: Messrs. Wayne Wallace Gutzman, Richard Albert Miller, Henry Vernon Price, Fred D. Rigby, and Carl Elof Sealander.

University of Kentucky: Mr. William Hicks Pell.

Northwestern University: Messrs. Clifford Gunnar Erickson, Howard K. Hilton, and Harold E. Wilson.

University of Pennsylvania: Mr. William Nathan Huff.

College of Saint Thomas: Mr. Michael Joseph Norris.

Stanford University: Messrs. Charles R. Bubb, Harry Earl Goheen, and Charles Douglas Olds.

University of Virginia: Mr. Alexander Doniphan Wallace.

University of Washington: Messrs. William Dwight Duthie and Richard Edward Johnson.

Department of Mathematics, Wayne University: Mr. I. Theodore Weinberg.

Department of Mathematics, Wellesley College: Martha Hathaway Plass.

Wesleyan University: Miss Mary Jane Kingman.

Western and Southern Life Insurance Company: Mr. Clifford Hartman Folz.

University of Wisconsin: Messrs. Randolph Hudie Cole, Cornelius Joseph Everett, 
Buford Echols Gatewood, Wilbur Charles McDaniel, and Wilbur Leonard Mitchell.

Department of Mathematics, Yale University: Messrs. Robert Abraham Rosenbaum, Bryce Townsend Ruley, Irving Ezra Segal, and Eric Avern Sturley.

The Secretary reported that Mr. Rama Shankar Varma, M.Sc., of Christ Church College, Cawnpore, India, and Mr. John Conrad Jaeger, M.A., Lecturer, University of Tasmania, Hobart, Tasmania, have been admitted to membership in the Society in accordance with the reciprocity agreement with the London Mathematical Society.

The Secretary reported that the membership in the Society is now 2,127 , including 127 contributing members., 175 nominees of institutional members, and 78 life members. There are also 88 institutional members. The total attendance of members at all meetings in 1937 was 1337; the number of papers read was 430 ; the number of hour lectures was 16 ; the number of members attending at least one meeting was 784 .

The reports of the Treasurer and of the Auditors (Mr. S. A. Joffe and Professor A. E. Meder) showed a balance of $\$ 18,142.71$ for the year ending November 30,1937, exclusive of the balances in the Colloquium Fund, Sinking Fund, and special funds. From this balance several printing bills for 1937 must be paid. It was pointed out that the expenses for 1937 are considerably below the total figures for 1935 and 1936 because, during 1935 and 1936, the Society acted as agent for the expenditure of money for extra activities not normally included in the budget. The regular budgetary expenditures have increased only slightly during the last few years. The Society's investments including Endowment Fund, Sinking Fund, and other special funds had a market value on November 30,1937 , of $\$ 90,396.75$. The net interest income for the year was $\$ 3,796.64$; dues from institutional memberships amounted to $\$ 6,429.75$; dues from contributing memberships, $\$ 1,201.97$; and dues from ordinary memberships were $\$ 12,873.54$. The Colloquium Fund showed a balance of $\$ 9,806.32$. The total received from the sale of the Society's publications was $\$ 10,029.00$. The expenditures included a grant of $\$ 2,500.00$ to the American Journal of Mathematics which is published jointly by the Society and the Johns Hopkins University. The trustees adopted a budget for 1938 showing estimated expenditures and receipts as $\$ 37,150$ and $\$ 38,346.07$, respectively. These items do not include a special budget for the Semicentennial Celebration.

The Librarian reported that the Library of the Society now contains 9,069 volumes.

The following appointments were reported: as auditors of the 
accounts for 1937, Mr. S. A. Joffe and Professor A. E. Meder, as representative on the National Research Council for the period beginning July 1, 1938, and to succeed Professor J. H. Van Vleck, Professor J. F. Ritt; as representatives on the Council of the American Association for the Advancement of Science for the year 1938, Professors R. E. Langer and F. D. Murnaghan; as committee to study the question of publicity for mathematics, Professor C. N. Moore (chairman), Dr. Saunders MacLane, and Professor G. B. Price.

The Bôcher Prize is to be awarded at the 1938 Annual Meeting to the author of a paper on Analysis appearing during the period 19331937.

A report from the Organizing Committee of the International Congress of Mathematicians states that the following subcommittees have been appointed: Budget Committee, Professors M. H. Ingraham (chairman), W. C. Graustein, Einar Hille, Marston Morse, Dean R. G. D. Richardson, and Professor D. V. Widder; Committee on Cooperation, Professors M. H. Stone (chairman), G. A. Bliss, Dr. E. R. Hedrick, Professors Dunham Jackson and Oswald Veblen; Entertainment Committee, Professors D. V. Widder (chairman), C. R. Adams, L. P. Copeland, and Philip Franklin, Dr. W. T. Martin, Dean R. G. D. Richardson, Mesdames G. D. Birkhoff, W. C. Graustein, and H. B. Phillips; Publicity Committee, Professors Philip Franklin (chairman), R. C. Archibald, and E. T. Bell, Mr. Garrett Birkhoff, and Professor Arnold Dresden. Plans are going forward satisfactorily. A budget for the early part of 1938 was adopted. The following sections have been tentatively authorized: (I) Algebra and Theory of Numbers; (II) Analysis; (III) Geometry and Topology; (IV) Probability, Statistics, Actuarial Science, Economics; (V) Mathematical Physics, Mechanics, Astronomy, Geophysics; (VI) Logic, Philosophy, History, Didactics.

The Rockefeller Foundation, the Institute for Advanced Study, and the National Research Council were thanked for generous subscriptions in support of the International Congress of Mathematicians.

The report presented by Professor Ingraham as chairman of the Committee on Fees at Meetings was adopted. This report recommended that Colloquium fees be abolished and that, in their place, registration fees for summer meetings be substituted. The registration fee would ordinarily be one dollar for each member of the organizations and fifty cents for each additional member of his family and for each guest. 
The following resolution regarding the death of Professor Morley was adopted:

The Council of the American Mathematical Society wishes to record its deep sense of loss at the death of Professor Frank Morley of the Johns Hopkins University. Those who knew him will long recall his gentlemanly dignity and unfailing courtesy. Professor Morley was one of the first members of the Society and lived to see it grow from modest beginnings to its present position as one of the leading mathematical organizations of the world. He served as editor of its Bulletin for several years and as its president during the years 1919-20. His services as editor-in-chief of the American Journal of Mathematics covered a long period of years, during part of which time the Society cooperated with the Johns Hopkins University in its publication. An account of his services to the Society and of his scientific abilities and attainments will appear in an early number of the Bulletin.

Additional times and places of meetings in 1938 were fixed as follows: Berkeley, April 9; New York, October 29; Cleveland, November 25-26; Los Angeles, November 26. Invitations were received from Ohio State University and Louisiana State University for the Annual Meeting in 1939.

It was announced that the October, 1938, number of the American Journal of Mathematics is to be dedicated to G. W. Hill, a former president of the Society, the one hundredth anniversary of whose birth takes place during 1938. Papers from leading mathematicians in fields allied to that of Dr. Hill will appear in this number.

Titles and cross references to the abstracts of papers read at the regular sessions follow below. The papers were read as follows: papers numbered 1 to 8 in the section for Algebra and Analysis on Tuesday morning; papers 9 to 16 in the section for Topology on Tuesday morning; papers 17 to 22 in the section for Analysis on Tuesday afternoon; papers 23 to 27 in the section for Geometry and Algebra on Tuesday afternoon; papers 28 to 33 in the general session on Wednesday morning; papers 34 to 39 in the section for Mathematical Logic on Wednesday afternoon; papers 40 to 45 in the section for Algebra on Wednesday afternoon; papers 46 to 51 in the section for Mathematical Statistics on Thursday morning; papers 52 to 59 in the section for Analysis on Thursday morning; and papers 60 to 93 , whose abstract numbers are followed by the letter $t$, were read by title. Of those presenting papers, Dr. Olaf Helmer was introduced by Professor Rudolf Carnap, Miss Audrey Wishard by Professor L. V. Ahlfors, and Professor Eugene Stephens by Professor Francis Regan. Paper 4 was presented by Professor G. A. Bliss, paper 9 by Dr. M. F. Smiley, paper 23 by Dr. S. B. Myers, and paper 47 by Professor H. T. Davis. 
1. A relative of the lemma of Schwarz, by E. F. Beckenbach. (Abstract 43-11-392.)

2. The completion of a Boolean ring and its application to integration, by H. M. MacNeille. (Abstract 44-1-36.)

3. Some existence theorems in the calculus of variations. I. Free problems, by E. J. McShane. (Abstract 44-1-86.)

4. Fields for multiple integrals of the calculus of variations, by G. A. Bliss, M. F. Smiley, and Leonidas Alaoglu. (Abstract 44-1-8.)

5. A general existence theorem for simultaneous equations, by $\mathrm{A}$. $\mathrm{H}$. Copeland. (Abstract 44-1-13.)

6. The remainder term for approximations of linear type, by W. E. Milne. (Abstract 44-1-40.)

7. Algebraic theory of abelian functions, by O. F. G. Schilling. (Abstract 44-1-57.)

8. An elementary derivation of the Uspensky quadrature formulas, by C. C. Torrance. (Abstract 44-1-88.)

9. Metric lattices, by M. F. Smiley and L. R. Wilcox. (Abstract 44-1-63.)

10. An existence theorem and some applications to topology, by A. N. Milgram. (Abstract 44-1-38.)

11. Symmetric and alternating products of circles, by A. W. Tucker. (Abstract 44-1-71.)

12. Complexes whose vertices have manifolds as linked complexes (preliminary report), by W. W. Flexner. (Abstract 44-1-19.)

13. Concerning upper semicontinuous collections and the decomposition of points of normal spaces, by R. G. Lubben. (Abstract 44-1-32.)

14. Theory of the topological order in linear topological spaces, by E. H. Rothe. (Abstract 44-1-56.)

15. On the characterization of abstract spaces by postulating the existence or non-existence of certain types of metrics, by $\mathrm{H}$. E. Vaughan. (Abstract 44-1-72.)

16. On the postulates for linear topological spaces, by E. W. Paxson. (Abstract 44-1-47.)

17. The Vitali covering theorem for Caratheodory linear measure, by J. F. Randolph. (Abstract 43-11-386.)

18. On expansions in solutions of differential equations, by M. G. Moore. (Abstract 44-1-42.)

19. Theory of functions of a complex variable defined over general sets, by W. J. Trjitzinsky. (Abstract 44-1-70.)

20. On the one dimensional Green's function, by W. M. Whyburn. (Abstract 44-1-78.)

21. The theory of integration, by G. B. Price. (Abstract 44-1-48.) 
22. On secant and tangent coefficients, by D. C. Harkin. (Abstract 44-1-22.)

23. The group of isometries of a Finsler manifold, by S. B. Myers and N. E. Steenrod. (Abstract 44-1-44.)

24. Deformations of the inner equator of a torus, by C. B. Tompkins (National Research Fellow). (Abstract 44-1-69.)

25. Abelian hypergroups (preliminary report), by H. S. Wall. (Abstract $44-1-73$.)

26. The maximum number of contacts of two algebraic surfaces, by T. R. Hollcroft. (Abstract 44-1-25.)

27. Matric conjugates in a ring $R(A)$, by $\mathrm{H}$. S. Thurston. (Abstract 44-1-68.)

28. Interior transformations on 2-dimensional manifolds, by G. T. Whyburn. (Abstract 44-1-77.)

29. Some inequalities in the theory of Fourier series, by Otto Szász. (Abstract 44-1-67.)

30. Quadratic null forms over a function field, by A. A. Albert. (Abstract 44-1-6.)

31. Metric spaces and positive definite functions, by I. J. Schoenberg. (Abstract 44-1-60.)

32. A theorem on relations and its applications to covering theorems of topology, by Karl Menger. (Abstract 44-1-37.)

33. Dirac equations and conditional invariants, by G. Y. Rainich. (Abstract 44-1-49.)

34. On the consistency of Quine's "New foundations for mathematical logic," by J. B. Rosser. (Abstract 44-1-54.)

35. The syntax of a language with infinite expressions, by Olaf Helmer. (Abstract 44-1-23.)

36. A theorem on deducibility for second-order functions, by $\mathrm{C}$. $\mathrm{H}$. Langford. (Abstract 44-1-30.)

37. A set of postulates for an algebra of $n$-valued logic, by D. L. Webb. (Abstract 44-1-75.)

38. On the categoricity of the postulates for Boolean algebra, by Paul Henle. (Abstract 44-1-24.)

39. On the reduction of Gentzen's calculus $L J$, by H. B. Curry. (Abstract 44-1-14.)

40. The transformation of bases of relative linear sets, by Margarete C. Wolf. (Abstract 44-1-80.)

41. Modularity in the theory of lattices, by L. R. Wilcox. (Abstract 44-1-79.)

42. Strict equivalence of matric pencils (preliminary report), by M. M. Flood. (Abstract 44-1-20.) 
43. Note on almost-universal forms, by P. R. Halmos. (Abstract 43-11-390.)

44. Commutative algebras which are polynomial algebras, by R. F. Rinehart. (Abstract 44-1-52.)

45. The uniqueness of the power series representation of certain fields and valuations, by Saunders MacLane. (Abstract 44-1-35.)

46. On a fiducial test of the significance of the difference of the means of two normally distributed populations which are not known to have equal variances, by Daisy M. Starkey. (Abstract 44-1-65.)

47. Some results in the theory of random series, by H. T. Davis and H. E. Jones. (Abstract 44-1-15.)

48. A moment-generating function which is useful in solving certain matching problems, by E. G. Olds. (Abstract 43-11-428.)

49. A rating table for card-matching experiments, by E. V. Huntington. (Abstract 44-1-84.)

50. Note on the probability distribution of a product, by B. H. Camp. (Abstract 44-1-10.)

51. The power function of the $\chi^{2}$-test, by Churchill Eisenhart. (Abstract 44-1-18.)

52. On the degree of approximation in some convergence theorems in conformal mapping, by S. E. Warschawski. (Abstract 44-1-74.)

53. The analog to the Cauchy integral and circulation functions of the second kind, by V. C. Poor. (Abstract 43-11-430.)

54. The interrelations among the fundamental solutions of the generalized hypergeometric equation when $p=q+1$. I. Non-logarithmic cases, by F. C. Smith. (Abstract 43-11-432.)

55. A theorem on generalized Jacobians, by Tibor Radó. (Abstract 43-11-388.)

56. Jackson summation of the Faber development, by W. E. Sewell. (Abstract 44-1-61.)

57. Some results concerning the behavior at infinity of real continuous solutions of algebraic difference equations, by O. E. Lancaster. (Abstract 43-11-427.)

58. On the absolute summability of Fourier series, by W. C. Randels. (Abstract 44-1-50.)

59. Some conditions on functions of bounded type, by Audrey Wishard. (Abstract 44-1-89.)

60. Polynomial approximations for elliptic functions, by E. T. Bell. (Abstract 44-1-7-t.)

61. Second order partial differential operators of elliptic type. Closure, by J. W. Calkin. (Abstract 44-1-9-t.)

62. Concerning Laplace transforms of periodic functions, by R. V. Churchill. (Abstract 44-1-11-t.) 
63. A line transformation related to reciprocal polars of a quadric surface, by J. M. Clarkson. (Abstract 44-1-12-t.)

64. The inverse of Meusnier's theorem in the geometry of element series, by J. J. De Cicco. (Abstract 44-1-16-t.)

65. Contractible problems of Bolza. II, by W. L. Duren. (Abstract 44-1-17-t.)

66. Extension formulas for interpolation with leading differences, by C. H. Forsyth. (Abstract 43-11-391-t.)

67. On hypergroups, multigroups, and product systems, by Lois W. Griffiths. (Abstract 44-1-21-t.)

68. The transformation of statistics to simplify their distributions, by Harold Hotelling and L. R. Frankel. (Abstract 44-1-26-t.)

69. The classification of element transformations by means of isogonal and equi-tangential series, by Edward Kasner and J. J. De Cicco. (Abstract 44-1-27-t.)

70. The geometry of the whirl-motion group $G_{6}$. Elementary invariants, by Edward Kasner and J. J. De Cicco. (Abstract 44-1-28-t.)

71. Geometry in an n-dimensional space with the arc length $s=\int\left(A_{i} x^{\prime \prime}{ }^{i}+B\right)^{1 / p} d t$, by Akitsugu Kawaguchi. (Abstract 43-11-389-t.)

72. Non-linear algebraic difference equations with formal solutions of the same type as the formal solutions of linear homogeneous difference equations, by O. E. Lancaster. (Abstract 44-1-29-t.)

73. On the equivalence of the nilpotent elements of a semi-simple ring, by Jakob Levitzki. (Abstract 44-1-31-t.)

74. Subrings of direct sums and related topics, by N. H. McCoy and Deane Montgomery. (Abstract 44-1-33-t.)

75. On the simultaneous approximation of a function and its derivatives by sums of Birkhoff type, by W. H. McEwen. (Abstract 44-1-34-t.)

76. On linear subsets of metric spaces, by Karl Menger and A. N. Milgram. (Abstract 44-1-39-t.)

77. On expansions in series of exponential functions, by M. G. Moore. (Abstract 44-1-41-t.)

78. A continuous function with no unilateral derivatives, by A. P. Morse. (Abstract 44-1-43-t.)

79. Relations between the coefficients of the modular representations of groups, by C. J. Nesbitt. (Abstract 44-1-45-t.)

80. Non-singular linear combinations of general forms, by Rufus Oldenburger. (Abstract 44-1-46-t.)

81. The Cauchy singular integral and circulation functions, by V. C. Poor. (Abstract 43-11-429-t.)

82. A theorem on quadratic forms, by W. T. Reid. (Abstract 44-151-t.) 
83. On periodic continued fractions, by W. C. Risselman. (Abstract 44-1-53-t.)

84. On the transformation group for diabolic magic squares of order four, by J. B. Rosser and R. J. Walker. (Abstract 44-1-55-t.)

85. A note on infinite perfect fields, by O. F. G. Schilling. (Abstract 44-1-58-t.)

86. On the structure of local class field theory, by O. F. G. Schilling. (Abstract 44-1-59-t.)

87. Remarks on the foundations of geometry, by A. R. Schweitzer. (Abstract 43-11-387-t.)

88. Note on the Faber coefficients of a continuous function, by W. E. Sewell. (Abstract 43-11-431-t.)

89. Affine differential geometry of plane curves from the point of view of Wilczynski, by H. A. Simmons. (Abstract 44-1-62-t.)

90. Torsion of regions bounded by circular arcs, by I. S. Sokolnikoff and Elizabeth S. Sokolnikoff. (Abstract 44-1-64-t.)

91. The purely operational solution of linear differential equations with polynomial coefficients, by EugeneStephens. (Abstract 44-1-66-t.)

92. Analytical methods in hypercomplex systems, by Olga Taussky. (Abstract 43-11-433-t.)

93. Interior transformations on certain curves, by G. T. Whyburn. (Abstract 44-1-76-t.)

T. R. HollCroft, Associate Secretary 